\title{
Application of Hydrothermally Modified Sweet Potato Starch as a Substitute Additive for Soup Mixture
}

\author{
S. A. Senanayake, ${ }^{1}$ K. K. D. S. Ranaweera, ${ }^{1}$ A. Gunaratne, ${ }^{2}$ and A. Bamunuarachchi ${ }^{1}$ \\ ${ }^{1}$ Department of Food Science and Technology, Faculty of Applied Sciences, University of Sri Jayewardenepura, \\ Gangodawila, Nugegoda, Sri Lanka \\ ${ }^{2}$ Department of Agriculture, University of Sabaragamuwa, Belihuloya, Sri Lanka
}

Correspondence should be addressed to S. A. Senanayake; surajisena@gmail.com

Received 17 June 2014; Revised 9 August 2014; Accepted 14 August 2014; Published 25 August 2014

Academic Editor: Harshadrai M. Rawel

Copyright (C) 2014 S. A. Senanayake et al. This is an open access article distributed under the Creative Commons Attribution License, which permits unrestricted use, distribution, and reproduction in any medium, provided the original work is properly cited.

\begin{abstract}
Potential application of modified sweet potato starch as a substitute thickener for corn starch was studied, by using native starches extracted from five different cultivars of sweet potatoes commonly available in Sri Lanka. Physicochemical properties (swelling power, water solubility index, pasting, and gelatinization) and digestibility of native and modified (heat-moisture treated, $20 \%$ moisture, $85^{\circ} \mathrm{C}$ for $6 \mathrm{hrs}$ ) starches were analysed. Modified Swp3 (Wariyapola white), Swp4 (Pallepola), and Swp5 (Malaysian) starches were selected based on the favourable conditions shown in the required physical and chemical properties and applied in a vegetable soup formula as a thickening aid. Corn starch added samples were kept as controls and the viscosity difference and sensory attributes were tested. Viscosity of the reconstituted soup powder and sensory analysis showed that Swp4 and Swp5 had significantly high level $(P<0.05)$ of sensory quality and the average rank for mouth feel (taste), texture and overall acceptability was significantly high $(P<0.05)$ in Swp5 added samples. Shelf life studies ensured 6 months of stability with negligible level of moisture increase and total plate count in air tight polypropylene packages at ambient temperatures $\left(28-31^{\circ} \mathrm{C}\right)$. Results of this study revealed a possibility of applying physically modified Swp4 and Swp5 starches as a substituent food ingredient for commercially available corn starch to improve the thickness of food products.
\end{abstract}

\section{Introduction}

The sweet potato (Ipomea batatas (L) Lam) is a tuberousrooted perennial plant belonging to the Convolvulaceae or morning glory family and the main commercial producers of sweet potatoes are China, Indonesia, Vietnam, Japan, India, and Uganda [1-3]. Sweet potato is a traditional crop in Sri Lanka and grown mainly in the wet and intermediate zones and nearly about 50,000 tons are produced annually [4]. All of this production is used for human consumption and the high consumer preference for roots prevents the utilization of it as an animal feed, since the production is insufficient [5]. Sweet potato is mainly consumed by low income people since it is one of the cheap substitutes for starchy staples such as rice, wheat, and potatoes [6] and contains a considerable level of starch, soluble sugars, vitamins, minerals, and other nutrients.
Sweet potato starch is being used worldwide in various food and industrial applications [7]. Native starches have limitations which reduce their use at industrial level due to the inability to tolerate a wide range of processing techniques, distribution, and storage conditions [8-10]. Modified starches are superior to native starches due to their improved functional properties and are widely employed in processed foods in recent years [11]. In Sri Lanka for food industrial applications corn starch is being used mostly as a thickening agent. The country's expenditure in importing this food ingredient is considerably high. In the year 2011 the country has imported about $8,794,286 \mathrm{~kg}$ for US $\$ 4,881,855$ [12]. Possible use of modified sweet potato starch as a thickening and viscosity enhancer was studied using five different cultivars of commonly available sweet potatoes in Sri Lanka. The most commercially viable heat-moisture treatment condition was selected based on our previous findings on swelling power, 
water solubility index, and the percentage digestibility of these cultivars [1-3]. Viscosity change and the sensory quality of the final soup mixture were used in the selection of the most suitable physically modified starch for potential application as a thickening agent.

\section{Materials and Methods}

Matured tubers of sweet potatoes, namely, Swp1 (Wariyapola red), Swp3 (Wariyapola white), Swp4 (Pallepola variety), Swp5 (Malaysian variety), and Swp7 (CARI 273) were randomly collected from Dhambulla, Horana, and Gokarella areas in Sri Lanka and prepared for analysis two to three days after harvesting.

2.1. Starch Extraction. Starch extraction was carried out according to the method described by Takeda et al. [13]. Fresh tubers were washed, peeled, and diced. Dipped in ice water containing $100 \mathrm{ppm}$ sodium metabisulphite to minimize browning and was wet milled at high speed in a laboratory scale blender with 1:2 w/v of tap water for 1 minute and filtered through a gauze cloth. Residue was repeatedly wet milled and filtered thrice and suspension was kept overnight for settling of starch. The supernatant was decanted and the settled residue was further purified with repeated suspension in tap water $(1: 2 \mathrm{v} / \mathrm{v})$ followed by the settling for 24 hours. The purified starch was dried at $35^{\circ} \mathrm{C}$, sifted through $300 \mu \mathrm{m}$ sieve, sealed, and packed for analysis.

2.2. Swelling Power (SP), Water Solubility Index (WSI), and Gelatinization. SP, WSI, and gelatinization enthalpy were determined by methods described by Gunaratne et al. [14]. Starch (100 mg, db) was weighed directly into a screw-cap test tube, and $10 \mathrm{~mL}$ distilled water was added. The capped tubes were placed on a vortex mixer for 10 seconds and incubated at $85^{\circ} \mathrm{C}$ water bath for 30 minutes with frequent mixing. The tubes were cooled to room temperature in an iced water bath and centrifuged at $2000 \times \mathrm{g}$ for 30 minutes; the supernatant was removed and remaining sediment in the tube was weighed $\left(W_{s}\right)$. The supernatant was dried to constant weight $\left(W_{1}\right)$ in a drying oven at $100^{\circ} \mathrm{C}$. The water swelling power was calculated as follows:

$$
\mathrm{SP}=\frac{W_{s}}{[0.1 \times(100 \%-\mathrm{WSI})]}\left(\frac{g}{g}\right)
$$

where

$$
\mathrm{WSI}=\frac{W_{1}}{0.1} \times 100 \%
$$

Gelatinization properties of the native starches were obtained through thermograms using a TA 2920 modulated DSC thermal analyzer and differential scanning calorimeter (DSC) equipped with a thermal analysis data station (TA Instruments, Newcastle, DE). Starch (3 mg) was weighed onto the aluminum DSC pan and distilled water $(9 \mu \mathrm{L})$ was added with a microsyringe. Pans were sealed and allowed to stand for $1 \mathrm{~h}$ at room temperature. The scanning temperature range and heating rate were $30-140^{\circ} \mathrm{C}$ and $10^{\circ} \mathrm{C} / \mathrm{min}$, respectively, using an empty pan as a reference.

2.3. Pasting Properties. Pasting properties of the native and physically modified starches were determined in triplicate replications using a rapid viscoanalyzer (RVA) model 3D (Newport Scientific, Warriiewood, Australia). Flour (3.5 g, $14 \%$ moisture basis) was mixed with distilled water (25 g) in the canister and loaded using STD2 heating and cooling profile.

2.4. Percentage Digestibility. Starch digestibility was measured by the method described by, [7]. A sample of $500 \mathrm{mg}$ was placed in a weighed centrifuge tube (Tarsons, $50 \mathrm{~mL}$ ) with addition of $15 \mathrm{~mL}$ phosphate buffer $(0.15 \mathrm{M}, \mathrm{pH} 6.5)$, $30 \mathrm{mg} \mathrm{CaCl}, 30 \mathrm{mg}$ gelatin, and $30 \mathrm{mg}$ pancreatin (Sigma Co., St. Louis, MO). The capped tubes were placed in a shaking water bath at $37^{\circ} \mathrm{C}$ with a sufficient speed to keep the flour in suspension for $12 \mathrm{hrs}$ and stopped the reaction with $5 \mathrm{~mL}$ of $1 \% \mathrm{H}_{2} \mathrm{SO}_{4}$. The suspension was centrifuged at $20,000 \times \mathrm{g}$ for 10 minutes and the supernatant was decanted and the residue pellet was dispersed with $15 \mathrm{~mL}$ of $80 \%$ ethanol and recentrifuged for 5 minutes. The supernatant was decanted and the tubes with the residue pellet were dried at $50^{\circ} \mathrm{C}$ for $6 \mathrm{hrs}$ and then at $80^{\circ} \mathrm{C}$ to constant weight, cooled, and weighed. Starch digestibility was expressed as percent weight loss after digestion. A blank without pancreatin was included for each sample to adjust the results.

2.5. Heat-Moisture Treatment (HMT) of the Extracted Starch. Approximately $20 \mathrm{~g}$ of starch was taken and adjusted the moisture levels to $20 \%$ and placed the moisture adjusted samples in tubes with a sealing cap and equilibrated at room temperature for $24 \mathrm{~h}$. Samples were heated at $85^{\circ} \mathrm{C}$ for $6 \mathrm{~h}$. Occasional shaking was done to samples within the treatment period for homogeneous distribution of moisture. After treatment, the samples were cooled to room temperature and dried at $40^{\circ} \mathrm{C}$ to a uniform moisture level of $10 \%$ and equilibrated at room temperature for 2 days.

2.6. Formulation of Vegetable Soup Mixture and Viscosity Analysis. A vegetable soup mixture was formulated with steamed and dehydrated dhal (40\%), carrot powder $(25 \%)$, leeks (14\%), tomatoes (3\%), salt (2.5\%), modified starch (2\%), white pepper $(1.5 \%)$, garlic (1\%), cinnamon, and curry leaves ( $0.5 \%$ each). Approximately $5.5 \mathrm{~g}$ of powder was reconstituted with $100 \mathrm{~mL}$ of boiling water and was simmered for 5 minutes. Temperature was brought down to $35^{\circ} \mathrm{C}$ and the viscosity was measured using a viscometer (Brookfield RVT, 206480, USA).

2.7. Sensory Analysis of Soup Mixture. Heat moisture treated Swp3, Swp4, Swp5, and corn starch as the control; added soup mixtures were reconstituted and the sample codes of 227, 257,217 , and 242 were given, respectively. Five-point unipolar hedonic scale was used. Untrained males and females of the ages between 20 to 30 years were used as panelists (30) 
TABLE 1: Physicochemical properties of sweet potato starches.

\begin{tabular}{|c|c|c|c|c|c|}
\hline Sample & $\mathrm{SP}(\mathrm{g} / \mathrm{g})$ & WSI (\%) & PV (RVU) & Gelatinization $\Delta H(\mathrm{j} / \mathrm{g})$ & Digestibility (\%) \\
\hline Swp1 & $7.9 \pm 0.1^{c}$ & $1.6 \pm 0.1^{\mathrm{e}}$ & $222 \pm 4.5^{\mathrm{b}}$ & $15.7 \pm 0.4^{\mathrm{b}}$ & $21.7 \pm 0.7^{\mathrm{b}}$ \\
\hline Swp3 & $8.7 \pm 0.2^{\mathrm{c}}$ & $1.8 \pm 0.1^{\mathrm{e}}$ & $225 \pm 2.1^{\mathrm{b}}$ & $16.4 \pm 0.7^{\mathrm{b}}$ & $21.9 \pm 1.5^{\mathrm{b}}$ \\
\hline Swp4 & $8.7 \pm 0.1^{c}$ & $1.3 \pm 0.1^{\mathrm{f}}$ & $257 \pm 4.2^{\mathrm{a}}$ & $14.3 \pm 0.3^{c}$ & $23.5 \pm 0.9^{b}$ \\
\hline Swp5 & $8.0 \pm 0.1^{\mathrm{c}}$ & $2.1 \pm 0.1^{\mathrm{d}}$ & $248 \pm 3.2^{\mathrm{a}}$ & $13.0 \pm 0.4^{\mathrm{d}}$ & $23.5 \pm 0.4^{\mathrm{b}}$ \\
\hline Swp7 & $5.8 \pm 0.1^{\mathrm{d}}$ & $0.5 \pm 0.1^{\mathrm{g}}$ & $214 \pm 4.1^{c}$ & $20.1 \pm 0.5^{\mathrm{a}}$ & $19.3 \pm 0.3^{c}$ \\
\hline${ }^{*}$ Swpl & $11.5 \pm 1.2^{\mathrm{b}}$ & $3.9 \pm 0.2^{\mathrm{a}}$ & $212 \pm 2.1^{\mathrm{c}}$ & ndt & $13.2 \pm 0.3^{\mathrm{d}}$ \\
\hline${ }^{*}$ Swp3 & $12.0 \pm 0.9^{\mathrm{a}}$ & $3.2 \pm 0.3^{\mathrm{b}}$ & $258 \pm 2.6^{\mathrm{a}}$ & ndt & $23.5 \pm 0.9^{\mathrm{b}}$ \\
\hline${ }^{*}$ Swp 4 & $12.5 \pm 0.8^{\mathrm{a}}$ & $4.2 \pm 0.3^{\mathrm{a}}$ & $262 \pm 1.5^{\mathrm{a}}$ & ndt & $26.6 \pm 0.7^{\mathrm{a}}$ \\
\hline${ }^{*}$ Swp5 & $12.1 \pm 0.2^{\mathrm{a}}$ & $4.1 \pm 0.3^{\mathrm{a}}$ & $251 \pm 1.2^{\mathrm{a}}$ & ndt & $19.5 \pm 0.5^{\mathrm{c}}$ \\
\hline *Swp7 & $8.5 \pm 0.7^{\mathrm{c}}$ & $2.8 \pm 0.3^{c}$ & $202 \pm 1.5^{c}$ & ndt & $13.7 \pm 0.2^{\mathrm{d}}$ \\
\hline
\end{tabular}

Sources: $[2,3],{ }^{*}$ HMT starch, ndt: not determined; values are means of triplicate determinations \pm standard deviation and the values denoted by different superscripts in each column are significantly different at $P<0.05$.

to test the sensory properties of appearance, colour, aroma, thickness, taste, and the overall acceptability.

2.8. Shelf Life Analysis of Dehydrated Soup Mixture. Total viable cell count was carried out using the pour plate method [15] up to 6 months at one month of intervals. Nutrient agar was used for enumeration of bacteria. Random sample of $1 \mathrm{~g}$ was serially diluted with sterile distilled water up to $10^{-6}$. One $\mathrm{mL}$ aliquot from a $10^{-2}$ to $10^{-5}$ was transferred aseptically into sterile petri dishes. Approximately $15 \mathrm{~mL}$ of sterile melted and cooled nutrient agar into each petri dish. The inoculum was evenly mixed with media by rotating the plates and allowing solidifying. The inverted plate was incubated at $37^{\circ} \mathrm{C}$ for $48 \mathrm{~h}$ in an incubator. The total viable count was determined using a colony counter. Moisture content of the soup mixture packed in polypropylene packages at room temperature was monitored in each month using the moisture balance (SHIMDZU, MOC63u) for 6 months.

2.9. Statistical Analysis. MINITAB (ver 14) package was used for data analysis. Analysis of variance (ANOVA) with Tukey's test was performed to examine the differences in viscosity and shelf life study of the formulated soup mixture. Samples in triplicate were used and a significance level of $P \leq 0.05$ was applied. Sensory evaluation of formulated vegetable soup mix was carried out using Kruskal-Wallies nonparametric ANOVA method with five-point unipolar hedonic scale.

\section{Results and Discussion}

3.1. Physicochemical Properties. When considering the swelling power and water solubility index for hydrothermally modified starch Swp3, Swp4, and Swp5 showed significant increase than the other two cultivars (Table 1). Peak viscosity $(\mathrm{PV})$ increased due to hydrothermal treatment of these three cultivars than the native starches. Digestibility level of native starch was significantly higher $(P<0.05)$ except for Swp3 and Swp4 cultivars and physical modification has increased the digestibility level in Swp3 and Swp4.

Representing RVA data for HMT starches showed reduced level of PV and a large reduction in the granular break

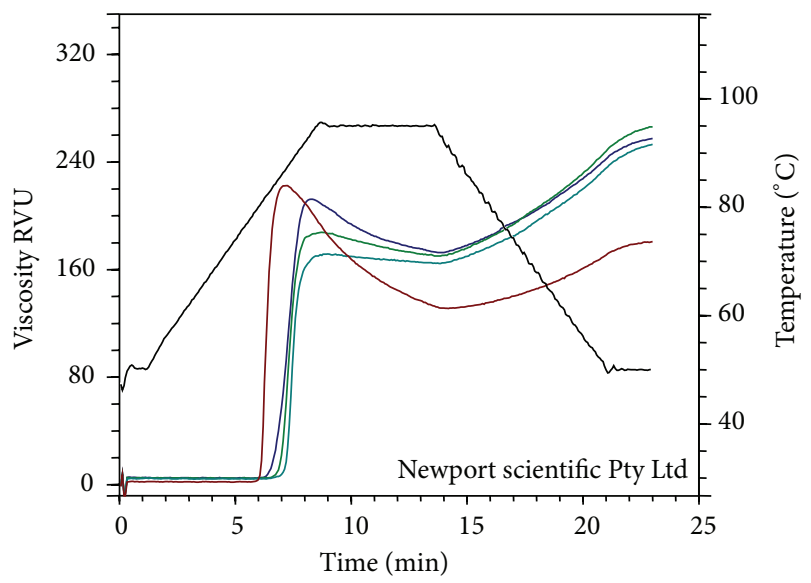

FIGURE 1: RVA curves of heat-moisture treated sweet potato starch (Swp1): viscosity curves from left to right represent the native, $(6 \mathrm{~h}$, $20 \%$ moisture, $\left.85^{\circ} \mathrm{C}\right),\left(6 \mathrm{~h}, 25 \%\right.$ moisture, $\left.85^{\circ} \mathrm{C}\right)$, and $(6 \mathrm{~h}, 30 \%$ moisture, $85^{\circ} \mathrm{C}$ ) treatment conditions.

down (BD). This indicated the ability of HMT treated starch to withstand high level of heating and shear stress while cooking. Hot paste viscosity increase was observed in all the HMT treated conditions compared to the native starches. Reduction of peak viscosity and BD indicates high level of paste stability in the treated starch (Figure 1). Based on the results shown for SP, WSI, and pasting properties Swp3, Swp4, and Swp5 cultivars may show more thickening capacity in food matrices.

3.2. Viscosity Change in Reconstituted Soup Mixtures. Comparatively lower viscosity was observed in control samples compared to the tested samples. Native form of Swp3 starch showed high level of viscosity in the soup mixture than its physically modified form (Figure 2). Heat-moisture treatment at $85^{\circ} \mathrm{C}$ and $20 \%$ has increased the viscosity of native starches except for Swp3 cultivar (Figure 2). High temperature has altered the crystalline structure of starch granules and increased the ability to make hydrogen bonds with water molecules [16-18]. As a result increased moisture 
TABLE 2: Average ranks of sensory attributes charts of sensory analysis for the developed formulas of soup mixtures.

\begin{tabular}{|c|c|c|c|c|c|c|}
\hline Treatment & Appearance & Colour & Texture (thickness) & Taste (mouth feel) & Aroma & Overall acceptability \\
\hline 227 (Swp3) & 50.8 & 54.5 & 59.7 & 56.4 & 54.8 & 48.4 \\
\hline 257 (Swp4) & 69.7 & 56.5 & 68.4 & 74.4 & 65.5 & 80.9 \\
\hline 217 (Swp5) & 79.2 & 63.5 & 72.2 & 64.7 & 71.1 & 69.2 \\
\hline 242 (control) & 42.3 & 67.4 & 41.8 & 46.6 & 53.7 & 53.7 \\
\hline
\end{tabular}

$N=30$ number of untrained male and female panelists between the ages of $20-30$ yrs.

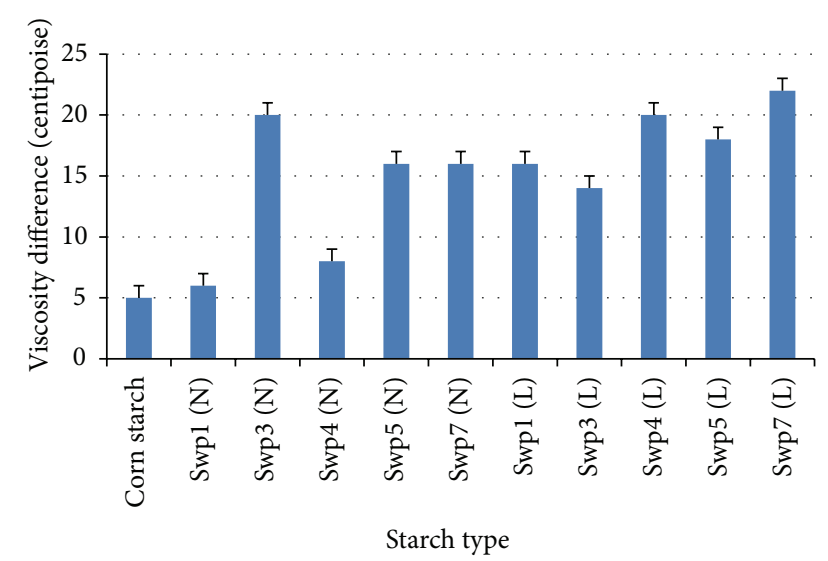

Figure 2: Viscosity change due to added starch. ${ }^{\text {a }}$ Swp- $(\mathrm{N})$ native starch. ${ }^{\mathrm{b}} \mathrm{Swp}-(\mathrm{L}) \mathrm{HMT}$ at $85^{\circ} \mathrm{C}$ and $20 \%$ moisture level for $6 \mathrm{hrs}$.

${ }^{\mathrm{C}}$ Results show the average values for triplicate samples.

level with altered crystalline structure has increased the SP and WSI of the HMT starch. High level moisture above the gelatinization temperature has increased the granular swelling, thus enhancing the level of viscosity [19]. Granular rearrangement due to heat-moisture treatment has reduced the viscosity in the Swp3 added sample.

There was no significant difference $(P<0.05)$ in the viscosity of the soup mixture with added native starches of Swp5, Swp7, and HMT Swp1 type. Combination of other ingredients in the soup mixture has increased the viscosity of the Swp7 added mix although the swelling power and WSI were low compared to other starches. Low percentage digestibility (Table 1) of Swp7 cultivar may prevent its possible usage as a thickener though it showed high level of final thickness in the soup mixture.

3.3. Sensory Analysis of the Soup Mixture. Sensory studies showed that all four samples were significantly different in appearance, colour, texture, aroma, and overall acceptability and there was no significant difference in taste $(P<0.05)$ in samples with added Swp3 and Swp5 starch. Table 2 gives the average rank obtained for each attribute of the tested samples. Average ranks for aroma, taste, texture, appearance, and overall acceptability were significantly high for formulas prepared with modified Swp5 and Swp4 starches while Swp4 had the highest level of overall acceptability. Corn starch added sample ranked high in the colour preference attribute only (Table 2). Thickness given by the added sweet potato starch was significantly higher than the corn starch. Our

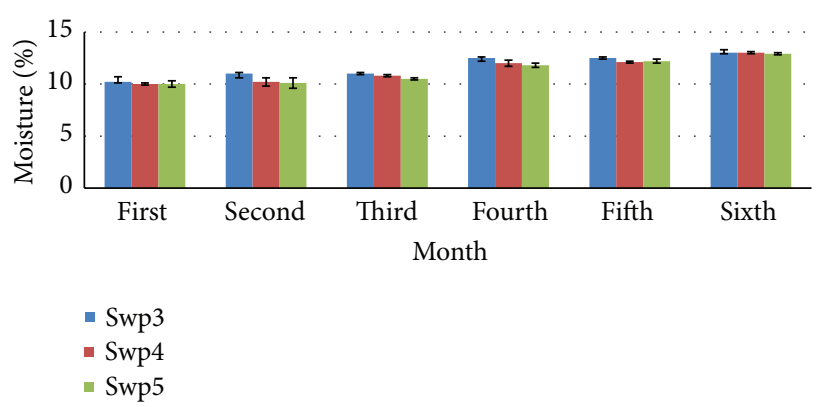

FIGURE 3: Level of moisture in packed mixture for 6 months period. (Standard deviation is given by vertical bars.)

results showed that hydrothermally modified starch added samples were more superior to corn starch in sensory aspects except for the colour attribute. Therefore modified starches (Swp3, Swp4, and Swp5) can be successfully substituted to corn starch as a thickener with higher level of sensory acceptability.

3.4. Analysis of Shelf Life. Moisture content and colony forming units in $1 \mathrm{~g}$ of the dry mix were significantly lower $(P<$ 0.05 ) in polypropylene packages for the period of 6 months at ambient temperature. Shelf life studies showed a significantly low level $(P<0.05)$ of moisture increase in all the samples during the 6-month time period. Maximum moisture level that can be present in wheat flour is 14\% [20]. Moisture percentage after 6 months of time was also less than 14\% in all the samples and this showed that these samples can be kept for a further period if the temperature and humidity control measures were taken (Figure 3). Initial level of microorganisms in all the tested samples was comparatively lower and slightly increased after the fourth month in Swp3 and Swp4 samples (Table 3).

This slight increase in the cfu may be due to the favourable increase of moisture \% within the environment after the fourth month. Although the increase of moisture took place, low water activity has restricted the growth rate of microorganisms. Results showed a positive correlation of the cfu and moisture content and initial level of microbial load may also be a reason to have a comparatively high level of microbes in Swp3 sample compared to the other two samples. According to standards maximum level of aerobic plate count is $10^{6} \mathrm{cfu} / \mathrm{g}$ at $35^{\circ} \mathrm{C}$ for dry soup powders [21]. The number of the cfu/g we observed for all three samples was much lower compared to 
TABle 3: Total plate count (cfu/g) within 6 month period.

\begin{tabular}{lccccccc}
\hline Sample & Initial level & 1st month & 2nd month & 3rd month & 4th month & 5th month & 6th month \\
\hline Swp3 & 2 & 2 & 2 & 5 & $7 \times 10^{1}$ & $3 \times 10^{2}$ & $2 \times 10^{3}$ \\
Swp4 & 0 & 0 & 2 & 5 & $1 \times 10^{1}$ & $2 \times 10^{1}$ & 35 \\
Swp5 & 0 & 0 & 2 & 2 & 2 & 7 \\
\hline
\end{tabular}

Samples were triplicated and average cfu/g (colony forming units per gram) was taken.

the maximum allowable level. Therefore the microbial safety of the product can be assured for a further period of time.

\section{Conclusion}

Our study reveals a potential application of hydrothermally modified sweet potato starch as a substitute thickener for food mixtures that gives a high level of viscosity than the commercially available corn starch. Modified forms of tested starches showed significant variations in the thickening when reconstituted in the soup mixture. Swp4 and Swp5 cultivars ranked high in sensory attributes of appearance, taste, aroma, and overall acceptability. Dry soup powder had 6-month shelf life and hydrothermal treatment to native sweet potato starch can enhance its thickening capacity and can be successfully substituted to corn starch as a food additive in viscosity enhancement.

\section{Conflict of Interests}

The authors declare that there is no conflict of interests regarding the publication of this paper.

\section{References}

[1] S. A. Senanayake, K. K. D. S. Ranaweera, A. Gunaratne, and A. Bamunuarachchi, "Comparative analysis of nutritional quality of five different cultivars of sweet potatoes (Ipomea batatas (L) Lam) in Sri Lanka," Food Science \& Nutrition, vol. 4, pp. 284291, 2013.

[2] S. A. Senanayake, K. K. D. S. Ranaweera, A. Gunaratne, and A. Bamunuarachchi, "Physico chemical properties of five cultivars of sweet potato (Ipomea batatas (L) Lam) roots grown in Sri Lanka," Tropical Agriculture, vol. 90, no. 1, pp. 96-110, 2013.

[3] S. Senanayake, A. Gunaratne, K. K. D. S. Ranaweera, and A. Bamunuarachchi, "Effect of heat moisture treatment conditions on swelling power and water soluble index of different cultivars of sweet potato (Ipomea batatas (L). Lam) starch," ISRN Agronomy, vol. 2013, Article ID 502457, 4 pages, 2013.

[4] http://faostat.fao.org/site/573/default.aspx.

[5] D. Zhang, W. W. Collins, and M. Andrade, "Genotype and fertilization effects on trypsin inhibitor activity in sweetpotato," HortScience, vol. 33, no. 2, pp. 225-228, 1998.

[6] K. P. U. de Silva and S. D. C. Jayawardene, Indigenous and Recent Advances in Sweet Potato Production, Processing and Marketing in Sri Lanka, 1989.

[7] Z. Zhang, C. C. Wheatley, and H. Corke, "Biochemical changes during storage of sweet potato roots differing in dry matter content," Postharvest Biology and Technology, vol. 24, no. 3, pp. 317-325, 2002.
[8] C. S. Raina, S. Singh, A. S. Bawa, and D. C. Saxena, "Some characteristics of acetylated, cross-linked and dual modified Indian rice starches," European Food Research and Technology, vol. 223, no. 4, pp. 561-570, 2006.

[9] S. Singh, C. S. Raina, A. S. Bawa, and D. C. Saxena, "Effect of heat-moisture treatment and acid modification on rheological, textural, and differential scanning calorimetry characteristics of sweetpotato starch," Journal of Food Science, vol. 70, no. 6, pp. E373-E378, 2005.

[10] J. Singh, L. Kaur, and O. J. McCarthy, "Factors influencing the physico-chemical, morphological, thermal and rheological properties of some chemically modified starches for food applications-a review," Food Hydrocolloids, vol. 21, no. 1, pp. 122, 2007.

[11] N. S. Sodhi and N. Singh, "Characteristics of acetylated starches prepared using starches separated from different rice cultivars," Journal Food Engineering, vol. 70, pp. 117-127, 2005.

[12] Trade > Imports > Sri Lanka, http://www.indexmundi.com/.

[13] Y. Takeda, A. Suzuki, and S. Hizukuri, "Influence of steeping conditions for kernels on some properties of corn starch," Starch, vol. 40, no. 4, pp. 132-135, 1988.

[14] A. Gunaratne, A. Bentota, Y. Z. Cai, L. Collado, and H. Corke, "Functional, digestibility, and antioxidant properties of brown and polished rice flour from traditional and new-improved varieties grown in Sri Lanka," Starch/Stärke, vol. 63, no. 8, pp. 485-492, 2011.

[15] F. Harrigan, M. C. Cance, and E. Margaret, Laboratory Methods of Food and Dairy Microbiology, Academic Press, London, UK, 1976.

[16] C. M. L. Franco, C. F. Ciacco, and D. Q. Tavares, "Effect of the heat-moisture treatment on the enzymatic susceptibility of corn starch granules," Starch-Stärke, vol. 47, no. 6, pp. 223-228, 1995.

[17] R. Stute, "Hydrothermal modification of starches: the difference between annealing and heat/moisture-treatment," StarchStärke, vol. 44, no. 6, pp. 205-214, 1992.

[18] R. F. Tester and S. J. J. Debon, "Annealing of starch-a review. Internationaltreatment on the enzymatic susceptibility of corn starch granules," Starch/Stärke, vol. 42, pp. 287-299, 2000.

[19] S. A. Senanayake, K. K. D. S. Ranaweera, A. Gunaratne, and A. Bamunuarachchi, "Effect of heatmoisture treatment on digestibility of different cultivars of sweet potato (Ipomea batatas (L.) Lam) starch," Food Science \& Nutrition, vol. 2, no. 4, pp. 398-402, 2014.

[20] The Gazette of the Democratic Socialist Republic of Sri Lanka, (Published by Authority) PART I : Section (I)-General, Food Act, no. 26, OF 1980.

[21] http://www.foodsafety.govt.nz/.../microbiological_referenceguide_assess.pdf. 

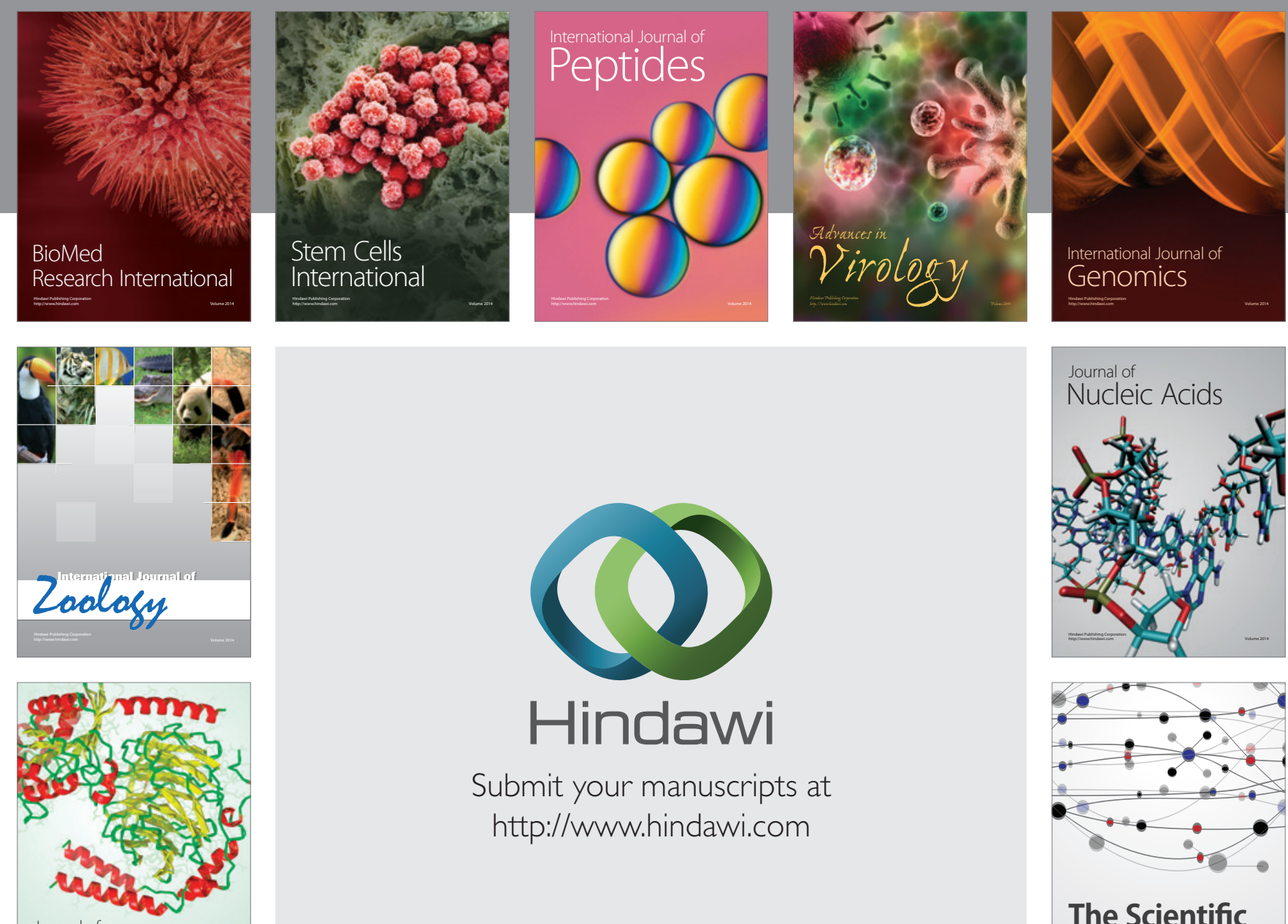

Submit your manuscripts at

http://www.hindawi.com

Journal of
Signal Transduction
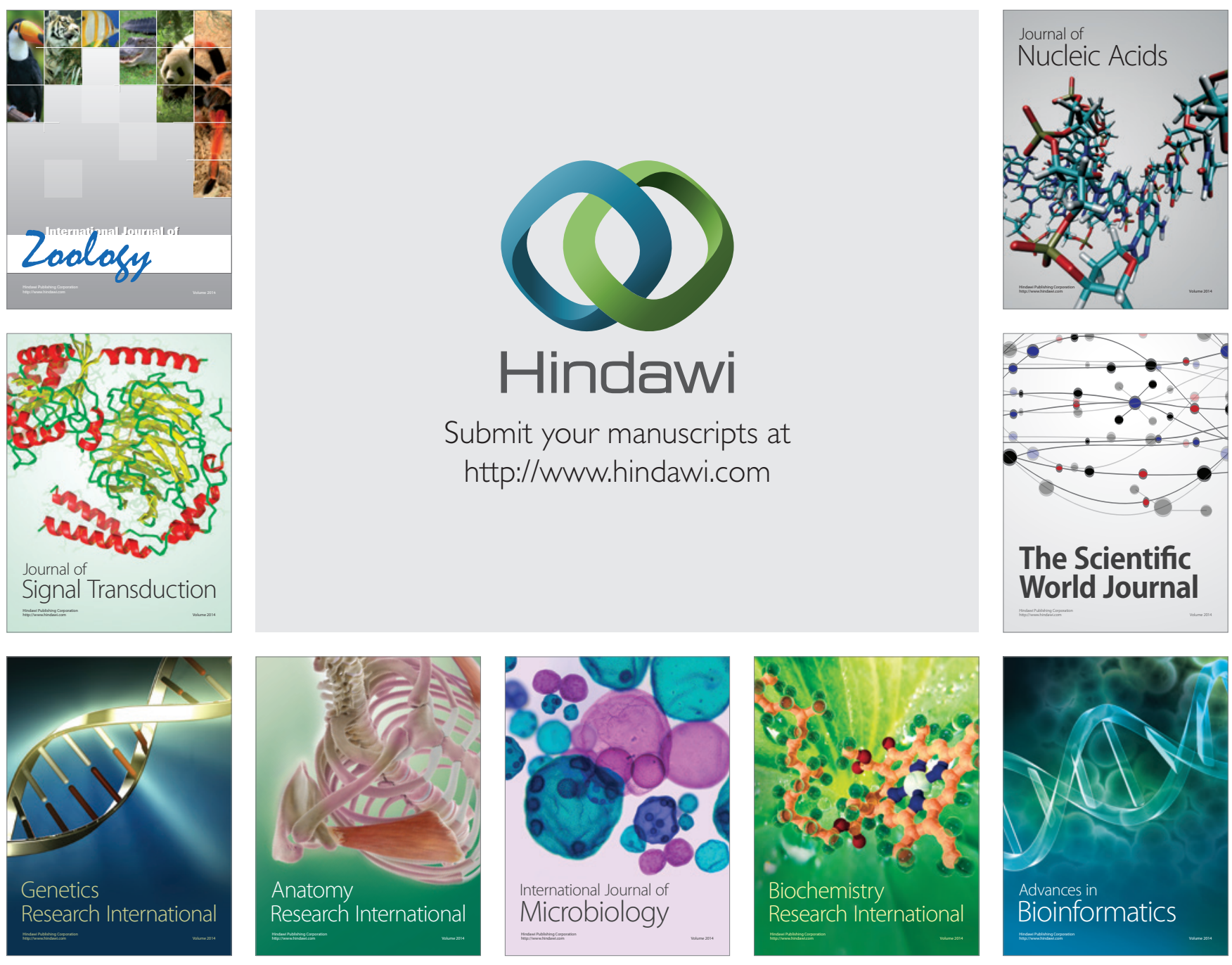

The Scientific World Journal
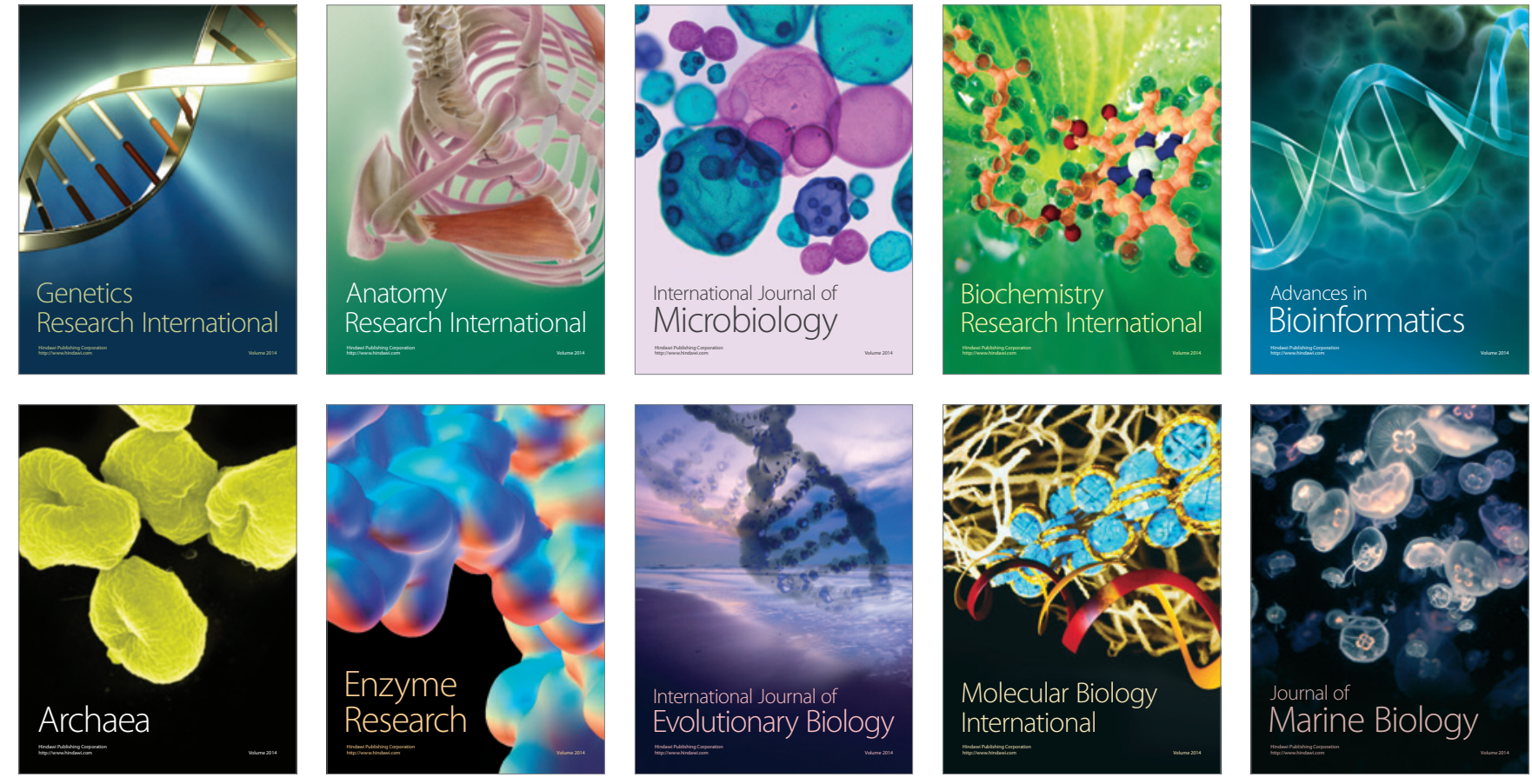